\title{
Matematik Öğretmenlerinin Kültürel Zekâ Düzeylerinin Belirlenmesi ve Çeşitli
}

\section{Değişkenler Açısından İncelenmesi* \\ Ayşegül ÇABUK AKSOP**, Duygu ÖZDEMİ*** ve Bilal ÖZÇAKIR****}

Öz: Bireysel farklılıkların en çok vurgulandığı eğitim alanında farklı gelenek, görenek, tutum ve beklentilere sahip çocukların eğitim öğretim ortamından maksimum düzeyde faydalanmalarını sağlamak ve bu çocuklar için kültüre duyarlı bir eğitim ortamı sağlamak önemli konulardan biri haline gelmiştir. Bu yüzden, farklı kültürlerden öğrencilerin eğitim öğretim sürecine dahil edilebilmesi, çok kültürlü eğitim ortamlarında öğrencilerin birbirlerini anlamaları, birlikte öğrenmeleri, uyumlu ve üretken bir şekilde çalışabilmeleri konusunda öğretmenlerin bu yüzyılda sahip olması gereken yeterliliklerin geliştirilebilmesi için kültürel zekâ kavramının incelenmesi zorunlu hale gelmiştir. Bu çalışmada matematik öğretmenlerinin kültürel zekâ düzeylerinin incelenmesi ve öğretmenlerin cinsiyetleri, yabancı dil bilgileri ile eğitim durumlarına göre kültürel zekâ düzeyleri ile kültürel zekanın alt boyutlarından üst biliş, biliş, davranış ve motivasyon arasında bir fark olup olmadığının tespit edilmesi amaçlanmıştır. Çalışma grubunu, 26 ilden katılım sağlayan 181 öğretmen oluşturmuştur. Çalışmada kesitsel tarama modeli kullanılmış olup veriler öğretmenlerden tek seferde "Kültürel Zekâ Ölçeği” kullanılarak toplanmıştır. Araştırma sonucuna göre matematik öğretmenlerinin kültürel zekâ düzeylerinin yüksek olduğu ve kültürel zekâ alt boyutları (üst biliş, biliş, davranış ve motivasyon) arasında anlamlı bir ilişki olduğu tespit edilmiştir. Ayrıca cinsiyet ve eğitim durumu kültürel zekâ puanları üzerinde anlamlı bir fark yaratmazken, yabancı dil bilme durumunun kültürel zekâ puanları üzerinde anlamlı bir fark yarattığı görülmüştür.

Anahtar Kelimeler: Kültür, kültürel zekâ, çok kültürlülük, matematik öğretmeni

\footnotetext{
*Bu araştırma için Alanya Alaaddin Keykubat Üniversitesi Sosyal ve Beşeri Bilimler Alanı Bilimsel Araştırma ve Yayın Etiği Kurul'undan (08.06.2021 tarih ve 05/26 numaralı) etik izin alınmıştır.

** Uzman, Türkiye Bilimsel ve Teknolojik Araştırma Kurumu, Email: aysegulcabuk@gmail.com, Orcid No: 0000-0002-1474-5981

*** Dr. Öğr. Üyesi, İstanbul Aydın Üniversitesi, Eğitim Fakültesi, Matematik ve Fen Bilimleri Eğitimi Bölümü, Email: duyguaydemr@gmail.com, Orcid No: 0000-0001-5841-3404

**** Dr. Öğr. Üyesi, Alanya Alaaddin Keykubat Üniversitesi, Eğitim Fakültesi, Matematik ve Fen Bilimleri Eğitimi Bölümü, Email: bilalozcakir@gmail.com, Orcid No: 0000-0003-2852-1791
} 


\section{Determining the Cultural Intelligence Levels of Mathematics Teachers and Examining them in terms of Various Variables}

Abstract: It has become necessity to examine the cultural intelligence concept in order to enable students from different cultures to be included in the educational process, to understand each other in multicultural environments, to learn together, to work in a harmonious and productive manner and to develop the qualifications that teachers should have in this century. In this study, it is aimed to investigate the cultural intelligence levels of mathematics teachers and to determine whether there is a significant difference between teachers' cultural intelligence levels according to some variables. The sample consisted of 181 mathematics teachers from 26 cities of Turkey. Cross-sectional survey method was used, and data were collected from teachers with "Cultural Intelligence Scale”. According to the results, teachers had high levels of cultural intelligence and there was a significant relationship among cultural intelligence dimensions (metacognition, cognition, behavioral and motivational). In addition, while gender and educational status did not cause significant difference on cultural intelligence levels of teachers, knowing a foreign language resulted with a significant difference on levels in cultural intelligence.

Keywords: Culture, cultural intelligence, multiculturalism, mathematics teacher.

\section{Giriş}

Küreselleşme ile ülkeler arasındaki sınırlar belirginliğini yitirmekte, farklı kültürlerden insanların etkileşimi artmakta ve bir arada yaşamak günlük yaşamın doğal bir parçası haline gelmektedir. Küreselleşmenin sonucu olarak ülkeler birbirine bağımlı hale gelmekte ve farklı ırk, uyruk, dil, din gibi değişkenler yanında farklı eğitim düzeyi ve sosyo ekonomik statüdeki insanlar etkileşimde bulunmaktadır. Sosyal etkileşimin en yoğun yaşandığı alanlardan birisi olan okullarda çok kültürlü bir ortam oluşmakta ve kültürel farklılıklar daha belirgin hale gelmektedir. Dolaysıyla bireysel farklılıkların en çok vurgulandığı eğitim alanında farklı gelenek, görenek, tutum ve beklentilere sahip çocukların eğitim öğretim ortamından maksimum düzeyde faydalanmalarını sağlamak ve bu çocuklar için kültüre duyarlı bir eğitim ortamı sağlamak önemli olmaya başlamıştır (Çoban, Karaman ve Doğan, 2010). 
Eğitim ve öğretim ortamını hazırlayan öğretmenlerin, farklı kültürlerden öğrencileri de kapsayabilmesi için gerekli olan öğretmen yeterliliklerine vurgu yapılmakta ve bu konu giderek önem kazanmaktadır (Koçak ve Özdemir, 2015). Özellikle çok kültürlü eğitim ortamlarında öğrencilerin birbirlerini anlamaları, birlikte öğrenmeleri, uyumlu ve üretken bir şekilde çalışabilmeleri konusunda en kritik görevi üstlenen öğretmenlerin bu konudaki yeterlilikleri ele alınmalı ve gerekli eğitim stratejileri geliştirilmelidir (Mcgregor ve Ungerleider, 1993). Bu anlamda öğretmenlerin çok kültürlü eğitim ortamlarında kültüre duyarlı davranış sergilemeleri ve buna yönelik beceriler geliştirilmesi için öğretmen yetiştirme sistemlerinin buna entegre edilmesi (Açıkalın, 2010) ve hizmet içi eğitimlerin sağlanması gerekmektedir. Sağlanacak eğitimlerin çatısını oluşturan çok kültürlülük eğitimi kavramı bireylerin kültürel farklılıklarına saygı duyulması ve her birine eşit öğrenme firsatının sağlanmasını da içeren genel bir eğitim politikasıdır (Polat ve Kılıç, 2013). Toplumun ihtiyaçlarının karşılanması ve bireye sunulan hizmetlerin niteliğinin artması amacıyla her ülkenin kendi eğitim politikası vardır ve bu politikanın uygulayıcısı olan öğretmenlerin sahip olduğu yeterliliklerin geliştirilebilmesi için kültürel zekâ kavramının incelenmesi önemlidir (Kuzu, Kuzu ve Gelbal, 2019).

Earley ve Ang (2003) tarafından kültürel zekâ, farklı kültürlerden gelen bireylerin olduğu ortamlarda etkin bir şekilde çalışabilme ve yönetebilme yeteneği olarak tanımlanırken; Ang, Van Dyne, Koh, Templar, Tay ve Chandrasekar (2007) ise kültürel zekayı, ırk, etnik köken ve uyruk farklılıklarının olduğu çok kültürlü ortamlardaki kültürlerarası etkileşimleri kapsayan çok boyutlu bir yapı olarak tanımlamıştır. Bu çok boyutlu yapı temelde kültürler hakkında bilgi sahibi olmayı, farklı kültür ortamlarında kişinin kültüre duyarlı hareket, davranış, reaksiyon ve öğrenme süreçleri geliştirebilme yeteneğini kapsamaktadır (Maznevski, 2006). Küreselleşme ve teknolojik gelişmelerin hızla ilerlediği 21 yüzyılda kültürel zekâ araştırmalarının değindikleri temel amaç kültürlerarası etkileşimi kolaylaştırmak ve geliştirmek (Earley, 2002), kültürel farklılıktan kaynaklı bireysel farklılıkların etkin bir şekilde anlaşılmasını sağlamaktır (Petrovic, 2011). Bu noktada kültürel zekâ kavramı eğitim alanında öğrencilerin kültürden kaynaklı bireysel farklılıklarının anlaşılmasında önemli bir kavram olacaktır. Özelikle farklı kültürlerden öğrencilerin bir araya geldiği okullarda öğrencilerin kültürel değerlerini anlama, kültürel farklıları etkili bir şekilde yöneterek uygun eğitim ortamını 
sağlama konusu etkili eğitim öğretim için gereklilik haline gelmiştir. Nitekim, eğitim öğretim sürecinde öğrencinin anlayışlarına uygun bir öğrenme ortamının ve öğretim sürecinin tasarlanması, kavramların anlamlandırılmasında oldukça önemlidir (Kuzu, Kuzu ve Sıvacı, 2018). Her bir öğrencinin birbirinden farklı olduğu bilinci ile hareket edilmesi gereken eğitim ortamlarında kültürel farklılıkların dikkate alınması, öğrencilerin öğrenme süreçlerinin kültürlere göre analiz edilmesi ve öğretim süreçlerinin kültürel bir harmanlama ile sunulmasında en önemli görev öğretmenlere düşmektedir. Öğretmenlerin bu görevi yerine getirebilmek için öncelikle çok kültürlü sınıf ortamlarındaki öğrencilerin birbiri ile uyum içerisinde çalışabilmeleri adına hangi becerileri geliştirmeleri gerektiği, bazı öğrencilerin farklı kültürlere daha iyi adapte olabilmelerinin sebeplerini ve öğrencilerin bu ortamlarda üretkenliğinin artırılabilmesi için hangi bilgi ve becerileri kazandırılması gerektiğini analiz edebilmelidir (Tan, 2004). Öğretim ortamlarında öğretmenlerin etkili bir eğitim öğretim ortamı oluşturabilmesi için kültürel zekâ düzeylerinin yüksek olması gerektiği ifade edilmektedir (Banks, 2013). Bu konuda yapılan çalışmalar incelendiğinde alan yazında sınırlı sayıda çalışmalar olduğu görülmüştür. Özellikle öğretmenlerin kültürel zekâ düzeylerinin belirlenmesi ve kültürel zekâ düzeyini açıklayan değişkenler üzerine detaylı çalışma yapılması konusunda alan yazında bir boşluk bulunmaktadır. Bu nedenle bu çalışmanın temel amacı öğretmenlerin kültürel zekâ düzeylerinin belirlenmesi ve kültürel zekâ düzeylerinin öğretmenlerin eğitim düzeyi, cinsiyet, yabancı dil bilmelerine göre anlamlı farklılık gösterip göstermediğini tespit edilmesidir.

\section{Araştırmanın Kuramsal Temeli ve İlgili Araştırmalar}

Kültürel zekâ kavramı temelde farklı kültürler içeren ortamlarda etkin şekilde çalışabilme yeteneği olarak tanımlanırken, kültürel zekâ çalışmalarının odağını bireylerin farklı kültürel ortamlara uyum sağlamasının sebeplerini araştırmak olduğu görülmektedir (Ang ve Dyne, 2008; Earley ve Ang, 2003). Çok boyutlu yapıdaki kültürel zekanın boyutlarına yönelik farklı sınıflandırmalar yapılmış ve bu sınıflamaların bazıları aşağıdaki tabloda verilmiştir (Thomas vd., 2008).

Tablo 1. Kültürel Zekâ Boyutları

\begin{tabular}{ll}
\hline Kaynak & Kültürel Zekâ Boyutları \\
\hline Earley, 2002; Early ve Ang, 2003 & Bilişsel, Motivasyonel ve Davranışsal \\
\hline Thomas ve Inkson, 2004 & Bilgi, Farkındalık, Davranış ve Beceriler \\
\hline
\end{tabular}




\begin{tabular}{ll}
\hline Early ve Masakowski, 2004 & Bilişsel, Fiziksel ve Duygusal \\
\hline Earley, Ang ve Tan, 2006 & Kültürel Stratejik Düşünme, Motivasyon ve \\
& Davranış \\
\hline Ang vd., 2007 & Bilişsel, Üstbilişsel, Motivasyonel ve \\
& Davranışsal \\
\hline
\end{tabular}

Yapılan sınıflamalar birbirinden farklı isimlendirilmiş olsa da her biri birbirini kapsar niteliktedir (Yeşil, 2010). Ang ve diğerlerinin (2007) sınıflamasına göre üstbilişsel boyut bireylerin farklı kültürler ile etkileşimi boyunca kültürlere ilişkin farkındalık bilinç düzeyini, bilişsel boyut bireyin kültürlere ilişkin normlar, adetler, uygulamalara dair eğitim ya da kişisel deneyimle öğrenilmiş bilgi düzeyini, motivasyonel boyut farklı kültürlere ilişkin deneyim yaşama ve diğer kültürleri öğrenmeye yönelik iç motivasyonunu, davranışsal boyut ise bireyin farklı kültürlerden insanlar ile iletişime geçerken sözlü veya sözsüz kendini ifade edebilme kapasitesini kapsar. Sonuç olarak kültürel zekâ tek bir kültüre odaklı bir kavram olmayıp farklı kültür ortamlarında yapabileceklerimiz ile ilgilidir.

Kapsamı ve uygulama alanı çok geniş olan kültürel zekâ, birçok farklı bilim dalının araştırma konusu olmuştur. Özellikle uluslararası araştırmalarda kültürel zekanın diğer zekâ türleri ile karşılaştırması yapılmış (Elenkov ve Pimentel 2008), kişilik özellikleri ve kültürel zekâ ilişkisini (Ang, Van Dyne ve Koh, 2006) incelenmiştir. Kültürel zekâ düzeyi ile ilişkili olabilecek değişkenlerin araştırıldığı çalışmalardan biri Tarıque ve Takeuchı (2008) tarafından yapılmış ve uluslararası çalışma deneyimi ile kültürel zekâ arasındaki ilişki incelenmiştir. Çalışmaya göre uluslararası çalışma deneyimi ile kültürel zekâ düzeyi arasında pozitif bir ilişki olduğu saptanmıştır. Ayrıca Earley ve Ang’’n (2003) kültürel zekânın geliştirilebileceğine yönelik vurguları Eisenberg, Lee, Brück, Brenner, Claes, Mironski ve Bell’in (2013) çalışmaları ile desteklenmiştir. Eisenberg ve diğerleri (2013) yaptıkları çalışmalarında kültürlerarası yönetim derslerinin öğrencilerin kültürel zekâ düzeylerine etkisi olup olmadığı araştırılmış ve derslerin özellikle öğrencilerin üstbilişsel ve bilişsel boyutları üzerinde anlamlı bir etkisi olduğu ortaya konulmuştur. Kültürel zekanın örgütler açısından faydalı olduğunun ortaya konulduğu bir çalışma da Flaherty (2008) tarafından yapılmıştır. Çalışmada çok kültürlü örgütlerde kültürel zekanın takım dinamiği üzerindeki etkileri araştırılmış ve takımın kültürel zekâ düzeyi ile yeni üyeleri kabul süreleri arasında pozitif bir ilişki bulunmuştur. Buna göre kültürel zekâsı yüksek olan takımların takıma yeni gelen 
üyeleri daha kolay kabul edebildiği ve yeni üyelerin takıma adaptasyonunun daha kolay sağlandığı yorumu yapılmıştır. Belirtilen çalışmalarda görüleceğgi üzere kültürel zekâ kavramı en temelde bir kültürlerarası işe ya da örgüte en uygun adayın nasıl belirleneceği sorusunun cevaplanmaya çalışıldığı alanların araştırma konusu olmuştur.

Türkiye'de kültürel zekâ konusunda sınırlı sayıda çalışmaya rastlanmıştır. Yeşil (2010) kültürel zekâ, kültür ve zekâ kavramlarının kuramsal çerçevesini incelemiştir. Şahin (2011) ise bir örgütte yaptığı çalışma ile liderlerin kültürel zekâ düzeylerinin astların örgütsel vatandaşlık davranışı ile iş doyumu üzerindeki etkilerini incelemiştir. Buna göre motivasyonel ve davranışsal boyutların etkili olduğu ortaya konmuştur. Ayrıca İşçi, Söylemez ve Kaptanoğlu Yıldırım (2013) tarafından sağlık çalışanlarının kültürel zekâ düzeyleri belirlenmiştir. Bu çalışmada mesleki deneyim süresinin kültürel zekanın davranışsal alt boyutu ve genel kültürel zekâ arasında negatif yönlü zayıf bir ilişki olduğu belirlenmiştir. Diğer bir çalışmada ise farklı kültürlerle etkileşim içerisinde olan uzak yol kaptanları ve uzak yol birinci zabıt katiplerinin kültürel zekâ düzeyleri incelenmiş ve katılımcıların motivasyonel kültürel zekâları önemli bir farkla daha yüksek çıktığı görülmüştür (Çetin, 2014). Türkiye'de matematik öğretmenlerinin kültürel zekâ düzeyine yönelik doğrudan bir çalışmaya rastlanmamış olup Koçak ve Özdemir (2015) öğretmen adaylarının çok kültürlü eğitime yönelik tutumları ile kültürel zekâları arasındaki ilişkiyi incelenmiştir. Çalışmada çok kültürlü eğitime olan tutum ile kültürel zekâ arasında pozitif bir ilişki olduğu ortaya konmuş ve demografik değişkenler ile kültürel zekaya ait üç boyutun (üst biliş, motivasyon ve davranış) çok kültürlü eğitime yönelik tutumun anlamlı yordayıcıları olduğu saptanmıştır. Sonuç olarak Türkiye'de matematik öğretmenlerinin kültürel zekâ düzeylerine ve bunların yordayıcısı olabilecek değişkenlere yönelik bir çalışma bulunmamaktadır. $\mathrm{Bu}$ durum öğretmenlerin kültürel zekâ düzeylerinin belirlenmesi ve bunların yordayıcısı olabilecek değişkenlerin araştırılmasını gerekli k1lmaktadır.

\section{Araştırmanın Önemi}

Kültürel etkileşimin yoğunlukla yaşandığı ortamlardan biri olan okullarda öğretmenlerin kültüre dayalı bir anlayış geliştirmeleri, kültürel farklılıkların sebep olduğu bireysel farklılıkları anlamaları ve öğrenme ortamını kültürel farklılıkları dikkate alarak düzenlemeleri etkili bir eğitim-öğretimin sağlanmasında önemli rol oynamaktadır (Çoban, Karaman ve Doğan, 2010). Bunun ön koşulu ise bireyin farklı kültürel ortamlarda 
etkin çalışabilme yeteneklerini konu alan (Ang, Van Dyne, Koh, Templar, Tay ve Chandrasekar, 2007) kültürel zekâ kavramını incelemek ve öğretmenlerin kültürel zekâ düzeylerini ve kültürel zekalarını geliştirilmesi için en etkili stratejileri ortaya koymaktır. Kültürel zekâ kavramı ilk olarak yurtdışında ya da çok kültürlü ortamlarda çalışacak en uygun adayı belirlemenin yolunu arayan araştırmacıların ilgisini çekti. Öyle ki yönetim ve örgüt psikolojisi kültürel zekâ kavramının en çok çalışıldığı alanlar olmuşlardır (Earley ve Ang, 2003; Earley ve Peterson, 2004). Buna ek olarak kapsamı ve uygulama alanı çok geniş olan kültürel zekâ kavramı farklı kültür ortamlarını ve bu ortamlardaki insanları anlamak isteyen birçok bilim dalının inceleme konusu olmaktadır. Bu dallardan biri olan eğitim alanında kültürel zekâ kavramı 2000'li yıllardan itibaren ele alınmaktadır.

2000'li yıllardan itibaren konuşulmaya başlanan kültürel zekâ kavramına yönelik alan yazın incelendiğinde bu konuda eğitim alanında özellikle öğretmen ve öğretmen adaylarına yönelik yapılmış sınırlı sayıda çalışma bulunmaktır (Koçak ve Özdemir, 2015). Bu çalışmalar doğrudan kültürel zekâya yönelik olmayıp temel konusu çok kültürlülüktür. Özelde çalışmalarda öğretmenlerin çok kültürlü eğitime yönelik tutumları (Çoban, Karaman ve Doğan, 2010), farkındalık düzeyleri (Karaçam ve Koca, 2012) ve çokkültürlülük hakkındaki düşünceleri (Tartwijk, Brok ve Wubbels, 2009) incelenmiştir. Sırbistan'daki öğretmenlerin kültürel zekâ düzeylerinin incelendiği çalışmada 107 ilköğretim öğretmeni ile çalışılmış ve öğretmenlerin kültürel zekâ düzeylerinin yüksek düzeyde olduğu bulgusu ortaya konulmuştur (Petorvic, 2011). Çalışmanın diğer bir katkısı ise farklı kültürlerle etkileşim içerisinde olmanın kültürel zekanın geliştirilmesi için tek başına yeterli olmadığı kültürlerarası etkileşimi sağlayan farklı ülkede eğitim almak, uluslararası bir işte çalışmak gibi etkinliklere katılımın kültürel zekanın geliştirilmesinde daha etkili olacağı yönündedir. Petrovic’in (2011) çalışmasının sonucunu destekler nitelikteki MacNab ve Worthney’ın (2007) kültürel zekanın geliştirilmesine yönelik becerilerin öğretilebileceğine yönelik vurgusu dikkate alındığında öğretmenlerin kültürel zekâ düzeylerinin belirlenmesi ve kültürel zekalarının geliştirilmesi için stratejilerin ortaya konulması önem taşımaktadır.

Bu noktada çok farklı kültürleri bünyesinde barındıran Türkiye'deki matematik öğretmenlerinin kültürel zekâ düzeylerinin belirlenmesi ve konunun farklı değişkenler açısından incelenmesine yönelik bir çalışmaya rastlanmamıştır. Dolayısıyla Türkiye'deki öğretmenlerin zekâ düzeylerinin incelenmesi önem taşımaktadır. Sonuç olarak bu çalışma 
ile öğretmenlerin kültürel zekâ düzeyleri belirlenecek ve kültürel zekâ düzeyleri eğitim düzeyi, cinsiyet, yabancı dil bilme durumu değişkenlerine göre incelenecektir.

\section{Araştırmanın Amacı}

$\mathrm{Bu}$ çalışmanın amacı matematik öğretmenlerinin kültürel zekâ düzeylerinin belirlenmesi ve kültürel zekâ düzeylerinin eğitim düzeyi, cinsiyet, yabancı dil bilme durumlarına göre anlamlı olarak farklılıklar gösterip göstermediğini tespit etmektir. Çalışmanın amacı doğrultusunda şu sorulara yanıtlar aranmıştır:

- Öğretmenlerin kültürel zekâ düzeyleri nedir?

- Öğretmenlerin kültürel zekâ düzeyleri ve kültürel zekanın alt boyutları arasında anlamlı bir ilişki var mıdır?

- Öğretmenlerin kültürel zekâ düzeyleri eğitim düzeyi, yabancı dil bilme durumu ve cinsiyetlerine göre anlamlı farklılık göstermekte midir?

\section{Yöntem}

\section{Araștırma Yöntemi}

Matematik öğretmenlerinin kültürel zekâ düzeylerinin belirlenmesi ve kültürel zekâ düzeylerinin eğitim düzeyi, cinsiyet, yabancı dil bilme durumu değişkenlerine göre incelenmesinin amaçlandığı bu çalışmada tarama modeli kullanılmıştır. Fraenkel ve Wallen'1n (2006) belirttiği üzere bir grup ya da topluluğun mevcut durumunun ortaya konması ya da belirli özelliklerinin tanımlanması için yapılan çalışma tarama çalışmasıdır. Bu nedenle çalışmanın amacına uygun olarak tarama modeli kullanılmıştır. Özelde ise bu çalışmada kesitsel tarama modeli kullanılmış olup veriler öğretmenlerden tek seferde Kültürel Zekâ Ölçeği kullanılarak toplanmıștır.

\section{Çalışma Grubu}

$\mathrm{Bu}$ araştırmanın evrenini Türkiye'de görev yapan 26 farklı ildeki matematik öğretmenleri oluşturmaktadır. Bu araştırmanın çalışma grubunu ise 26 ilden toplam 181 matematik öğretmeni oluşturmaktadır. Çalışma grubu olasılık dışı örneklem yöntemlerinden biri olan uygun örnekleme yöntemi ile oluşturulmuştur. Öyle ki çalışmaya ulaşılması kolay olan ve araştırmaya katılmak isteyen bireyler dahil edilmiştir (Fraenkel ve Wallen, 2006). Çalışma grubunda Türkiye'nin (yedi farklı coğrafi bölgesinde yer alan) çeşitli illerinde görev yapan matematik öğretmenleri yer almıştır. Çalışmadaki katılımcıların 133'ü kadın (\%73,5), 48'i erkek (\%26,5)'tir. Bu, katılımcıların 
$\% 61,9$ 'u lisans mezunu, $\% 26,5^{\prime}$ 'i yüksek lisans mezunu ve \%11,6's1 ise doktora mezunudur. Katılımcıların eğitim durumuna göre dağılımı ise Tablo 2'de verilmiştir.

Tablo 2. Katılımcıların Eğitim Durumu ve Cinsiyet Değişkenlerine Göre Dağılımı

\begin{tabular}{ll}
\hline Eğitim Durumu/Cinsiyet & Kişi Sayısı \\
\hline Lisans & 112 \\
Erkek & 29 \\
Kadın & 83 \\
\hline Yüksek Lisans & 48 \\
Erkek & 14 \\
Kadın & 34 \\
\hline Doktora & 21 \\
Erkek & 5 \\
Kadın & 16 \\
\hline Toplam & 181 \\
\hline
\end{tabular}

\section{Veri Toplama Araçları}

Araştırmada Ang ve diğerleri (2007) tarafından geliştirilen ve İlhan ve Çetin (2014) tarafından Türkçe uyarlama çalışması yapılan Kültürel Zekâ Ölçeği (KZÖ) kullanılmıştır. Kullanılan ölçek "hiç katılmıyorum" ile "tamamen katılıyorum" arasında değer alabilen 7'li likert tipi bir derecelendirmeye sahiptir. Ölçek üstbiliş, biliş, motivasyon ve davranış olmak üzere 4 alt boyut ve bu boyutlarda yer alan toplam 20 maddeden oluşmaktadır. Ölçeğin uyarlama çalışmasında açıklanan toplam varyans \%52,66 ve ölçeğin tümüne yönelik Cronbach alfa güvenirlik katsayısı 0,85 olarak hesaplanmıştır.

\section{Verilerin Toplanması ve Analizi}

KZÖ öğretmenlerin e-posta adreslerine gönderilmiş ve online olarak anketin doldurulması talep edilmiştir. Verilerin toplanması aşamasında öğretmenler kişisel bilgilerin gizliliği ve anketin doldurulmasında gönüllüğün esas olduğu ile anketi doldurmayı istedikleri anda bırakabilecekleri yönünde yazılı bilgilendirme yapılmıştır. Ayrıca öğretmenlere anketin tamamlanmasının yaklaşık 15 dakika sürdüğü bilgisi verilmiştir. Verilerin analizi için SPSS 20.0 programı kullanılmıştır. Toplanan verilerin ön analizlerine göre verilerin parametrik analizlerin varsayımlarını karşıladı $\breve{g}_{1}$ görülmüştür. $\mathrm{Bu}$ nedenle verilere ilişkin aritmetik ortalama ve standart sapmalar hesaplanmış ve bu verilerin analizinde Pearson Korelasyon testi, bağımsız örneklemler t- 
testi ve tek yönlü varyans analizi (ANOVA) kullanılmıştır. Kullanılan ölçeğin Cronbach alfa güvenirlik katsayısı bu çalışmada 0,84 olarak hesaplanmıştır.

\section{Bulgular}

Matematik öğretmenlerinin kültürel zekâ düzeylerinin belirlenmesi ve kültürel zekâ düzeylerinin eğitim düzeyi, cinsiyet, yabancı dil bilme durumu değişkenlerine göre incelenmesine yönelik analizler sonucunda elde edilen bulgular bu bölümde paylaşılmıştır. Öncelikle, çalışmada yer alan matematik öğretmenlerinin kültürel zekâları ve çalışmadaki veri toplama aracının alt boyutlarında aldıkları puan ortalamaları ve standart sapma puanları Tablo 3'te sunulmuştur.

Tablo 3. Öğretmenlerin kültürel zekâ ve alt boyutlarına ilişkin ortalama ve standart sapma değerleri

\begin{tabular}{llll}
\hline & $\mathrm{N}$ & Ortalama & Standart Sapma \\
\hline Üstbiliş & 181 & 5,88 & 1,03 \\
Biliş & 181 & 4,65 & 1,20 \\
Davranış & 181 & 5,25 & 1,28 \\
Motivasyon & 181 & 5,63 & 1,26 \\
Kültürel Zekâ & 181 & 5,29 & 0,99 \\
\hline
\end{tabular}

Tablo 3’te görüldügü üzere öğretmenlerin kültürel zekalarının $(\bar{X}=5,29$, SS= $0,99)$, üstbiliş alt boyutunun $(\bar{X}=5,88, \mathrm{SS}=1,03)$, biliş boyutunun $(\bar{X}=4,65, \mathrm{SS}=1,20)$, davranış boyutunun $(\bar{X}=5,25, \mathrm{SS}=1,28)$ ve motivasyon boyutunun $(\bar{X}=5,63$, SS=1,26) olduğu saptanmıştır. Bu değerlere göre, alt boyutlar bazında ortalamalar arasında küçük farklılıklar yer alsa da öğretmenlerin kültürel zekâ ve alt boyutlarına yönelik ortalamalarının genel olarak 7 üzerinden 5'e yakın olduğunu ve dolayısıyla kültürel zekâ düzeylerinin yüksek olduğunu görülmektedir. Öğretmenlerin kültürel zekâ alt boyutları arasında anlamlı bir ilişki olup olmadığının tespiti için aralarındaki korelasyon incelenmiş ve bu ilişkileri gösteren Pearson korelasyon testi sonuçları Tablo 4'te verilmiştir.

Tablo 4. Kültürel zekâ alt boyutları korelasyon katsayıları

\begin{tabular}{lllll}
\hline & Biliş & Motivasyon & Davranış & Üstbiliş \\
\hline Biliş & 1 & - & - & - \\
Motivasyon & $0,570^{*}$ & 1 & - & - \\
Davranış & $0,521^{*}$ & $0,652^{*}$ & 1 & - \\
Üstbiliş & $0,530^{*}$ & $0,575^{*}$ & $0,592^{*}$ & 1 \\
\hline
\end{tabular}


${ }^{*} \mathrm{p}<0,05$

Yapılan korelasyon incelemesine göre kültürel zeka alt boyutlarının (üstbiliş, biliş, motivasyon ve davranış) arasında anlamlı bir ilişki bulunmaktadır $(\mathrm{p}<0,05)$. Alt boyutların ilişki derecesi ise orta düzeydedir. Ayrıca bu ilişkinin yönü tüm boyutlar için pozitif yönlüdür. Yani kültürel zekâ düzeylerine ilişkin alt boyutlardan herhangi birine ilişkin düzeyi yüksek olan bir matematik öğretmeninin diğer alt boyutlardaki düzeyinin de yüksek olacağı beklenmektedir. Çalışmanın diğer bir araştırma sorusu olan öğretmenlerin kültürel zekâ düzeylerinin cinsiyete göre anlamlı bir farklılık gösterip gösterilmediğinin incelenmesi için bağımsız örneklem t-test analizi yapılmış ve Tablo 5’te t-test analiz sonuçları verilmiştir.

Tablo 5. Cinsiyete göre kültürel zekâ skorlarının t-testi sonuçları

\begin{tabular}{llllllll}
\hline & Cinsiyet & $\mathrm{N}$ & Ortalama & SS & sd & t & p \\
\hline Kültürel & Kadın & 133 & 5,27 & 0,95 & 179 & $-0,472$ & 0,637 \\
Zekâ & Erkek & 48 & 5,35 & 1,10 & & & \\
\hline
\end{tabular}

Tablo 5’te görüldüğü üzere matematik öğretmenlerinin cinsiyetlerine göre kültürel zekâ düzeylerinde anlamlı bir farklılık olmadı̆̆ 1 tespit edilmiştir $(\mathrm{t}(179)=-0,472$ , p>0,05). Buna göre, kadın matematik öğretmenlerinin kültürel zekâ düzeyleri ortalamaları $(\bar{X}=5,27, \mathrm{SS}=0,95)$ ile erkek matematik öğretmenlerinin kültürel zekâ düzeyleri ortalamaları $(\bar{X}=5,35, \mathrm{SS}=1,10)$ arasında anlamlı bir farklılık olmadığı yapılan analizlerle ortaya çıkmıştır. Çalışmanın diğer araştırma sorusuna yönelik, matematik öğretmenlerinin kültürel zekâ düzeylerinin yabancı dil bilme durumuna göre anlamlı bir farklılık gösterip gösterilmediğinin incelenmesi için de bağımsız örneklem t-test analizi yapılmış ve analiz sonuçları Tablo 6'da verilmiştir.

Tablo 6. Yabancı dil bilme durumuna göre kültürel zekâ skorlarının t-testi sonuçları

\begin{tabular}{llllllll}
\hline & $\begin{array}{l}\text { Yabancı Dil Bilme } \\
\text { Durumu }\end{array}$ & $\mathrm{N}$ & Ortalama & SS & sd & t & p \\
\hline Kültürel & Biliyorum & 140 & 5,39 & 0,98 & 179 & 2,68 & 0,008 \\
Zekâ & Bilmiyorum & 41 & 4,93 & 0,96 & & & \\
\hline
\end{tabular}

Tablo 6'da görüldüğü üzere, yabancı dil bilenler matematik öğretmenlerinin kültürel zekâ düzeyleri ortalamaları $(\bar{X}=5,39$, SS=0,98) ile bilmeyenlerin kültürel zekâ 
düzeyleri ortalamaları $(\bar{X}=4,93, \mathrm{SS}=0,96)$ arasında anlamlı bir farklılık bulunmaktadır $(\mathrm{t}(179)=2,68, \mathrm{p}<0,05)$. Buna göre, ortalamalara bakıldığında yabancı dil bilen matematik öğretmenlerinin kültürel zekâ düzeylerinin yabancı dil bilmeyen öğretmenlerden anlamlı şekilde yüksek olduğu sonucuna ulaşılmıştır. Bu farklılığa ilişkin etki büyüklüğü Cohen D ise 0,47 olarak hesaplanmıştır. Öğretmenlerin kültürel zekâ düzeylerinin eğitim düzeyine göre (lisans mezunu, yüksek lisans mezunu ve doktora mezunu) anlamlı farklılık gösterip gösterilmediğinin incelemesi için ANOVA testi yapılmış ve analiz sonuçları Tablo 7'de verilmiştir.

Tablo 7. Eğitim durumuna göre kültürel zekâ düzeylerinin ANOVA sonuçları

\begin{tabular}{llllll}
\hline Varyans Kaynağı & KT & sd & KO & F & p \\
\hline Gruplar arası & 2,89 & 2 & 1,45 & 1,471 & 0,232 \\
Grup içi & 174,82 & 178 & 0,98 & & \\
\hline
\end{tabular}

Tablo 7'ye göre, ANOVA sonuçları doktora derecesine sahip öğretmenlerin $(\bar{X}=4,97, \mathrm{SS}=1,21)$, yüksek lisans derecesine sahip öğretmenlerin $(\bar{X}=5,42$, SS $=0,94)$ ve yalnızca lisans derecesine sahip öğretmenlerin $(\bar{X}=5,29$, SS=0,94) kültürel zekâ düzeyleri ortalamaları arasında anlamlı bir farklılık olmadığını göstermiştir $(F(2,178)=1,471, p>$ 0,05). $\mathrm{Bu}$ nedenle, matematik öğretmenlerinin lisansüstü kademelerde eğitim almış olmalarının kültürel zekâları üzerine anlamlı bir etkisinin olmadığı yapılan analiz sonuçlarına göre görülmektedir.

\section{Tartışma ve Öneriler}

$\mathrm{Bu}$ araştırmada, matematik öğretmenlerinin kültürel zekâ düzeyleri ve kültürel zekâ alt boyutları cinsiyet, eğitim düzeyi ve yabancı dil bilme durumlarına göre incelenmiştir. Genel olarak analiz sonuçları incelendiğinde, çalışmaya katılan matematik öğretmenlerinin kültürel zekâ düzeylerinin yüksek olduğu tespit edilmiştir. Matematik öğretmenlerinin kültürel zekâ düzeylerinin yüksek çıkması alanyazında yer alan diğer araştırmalar ile uyumludur (İlhan ve Çetin, 2014; Koçak ve Özdemir, 2015; Kozikoğlu ve Tosun, 2020). Bu durumu Kozikoğlu ve Tosun (2020) öğretmenlerin farklı kültürlerle etkileşime duyarlı, farklı kültürlere karşı saygılı ve farklı kültürlerin varlığının farkında olmaları ile ilişkilendirmiştir. Çalışmada yer alan bulgulara göre, öğretmenlerin genel kültürel zekâlarının yanı sıra kültürel zekanın alt boyutları incelenmiş ve üstbiliş alt 
boyutuna yönelik skor ortalamalarının diğer boyutlardan daha yüksek olduğu görülmüştür. Bu durum genel olarak bireylerin farklı kültürel yapıların farkında olmaları ve önyargılarından arınarak bu kültürlerle etkileşime girebilmeleri olarak tanımlanmaktadır. Öğretmenlerin de özellikle öğretim ortamlarında farklı kültürlerden gelen bireylerle sürekli iç içe olmaları ile kültürel farkındalıklarının arttığı söylenebilir. Bu sonuç alanyazında yer alan farklı araştırmalar ile de uyumludur (İlhan ve Çetin, 2014; Koçak ve Özdemir, 2015). Ayrıca çalışmanın devamında yapılan analizlerde ise kültürel zekâ altboyutları arasında anlamlı bir ilişki olduğu saptanmıştır. Buna göre, üstbiliş zekâ boyutu yüksek olan bir bireyin diğer boyutlarının puanlarının da yüksek olması beklenmektedir.

Çalışmada cinsiyet, eğitim durumu ve yabancı dil bilme durumunun öğretmenlerin kültürel zekâ düzeylerinde anlamlı bir farka neden olup olmadığı araştırılmıştır. Bu amaçla ele alınan analiz sonuçlarında, öğretmenlerin cinsiyetleri ve eğitim durumlarının kültürel zekâ düzeyleri üzerinde anlamı bir fark oluşturmadığı görülürken, yabancı dil bilenlerin kültürel zekâ düzeyleri ile yabancı dil bilmeyenlerin kültürel zekâ düzeyleri arasında anlamlı bir fark olduğu tespit edilmiştir. Alanyazında yer alan çalışmalar incelendiğinde cinsiyet değişkeninin kültürel zekâ üzerine etkilerinin hem kadınlar lehine hem de erkekler lehine olduğunu gösteren çalışmaların yanında etkisinin olmadığını ifade eden çalışmaların da varlığı görülmektedir (Adıgüzel ve Aslım-Yetiş, 2021; İnan, 2017; Khodadady ve Gharari, 2011; Koçak ve Özdemir, 2015; Kozikoğlu ve Tosun, 2020; Maden ve Maden, 2018; Mahasneh, Gazo ve Al-Adamat, 2019; Mercan, 2016; Nikoopour ve Esfandiari, 2017). Bu çalışmada elde edilen, cinsiyetin kültürel zekâ düzeylerinde anlamlı bir farklılık oluşturmadığına ilişkin bulgular benzer çalışmalarla (Adigüzel ve Aslım-Yetiş, 2021; İnan, 2017; Mercan, 2016; Nikoopour ve Esfandiari, 2017) uyuşmaktadır. Buna rağmen alanyazında yer alan bazı çalışmalar kültürel zekâ düzeylerinin kadınların lehine anlamlı bir şekilde farklılaştığını gösterirken (Khodadady ve Ghariri, 2011; Koçak ve Özdemir, 2015), erkeklerin lehine anlamlı farklılık gösterdiğini bulan çalışmalar da yer almaktadır (Maden ve Maden, 2018; Mahasneh, Gazo ve Al-Adamat, 2019). Genel olarak alanyazın incelendiğinde, araştırmalarda cinsiyet değişkeni ile kültürel zekâ düzeyleri arasındaki ilişkiye yönelik farklı sonuçlara ulaşıldığı görülmektedir. Bu farklı sonuçlar, araştırmanın yürütüldüğü örneklemlerin özelliklerinden kaynaklanabilme ihtimali de bulunmaktadır. Bu nedenle, bu çalışmanın 
bulgularından hareketle, farklı cinsiyetlerdeki öğretmenlerin kültürel zekâ düzeylerinin birbirinden anlamlı olarak farklı olmadığı ve kültürel zekanın başka değişken tarafından etkilenebileceği söylenebilir. Bunun yanında, çalışmanın bulgularına göre matematik öğretmenlerinin eğitim düzeyleri ile kültürel zekâ düzeyleri arasında anlamlı bir farklılık görülmemiştir. Peköz (2018) çalışmasında da genel kültürel zekâ düzeyleri ile öğretmenlerin son mezun oldukları eğitim kademesi arasında anlamlı bir ilişkiye rastlamamasına karşın kültürel zekanın alt boyutlarından davranış boyutunda anlamlı bir farklılığın olduğunu belirtmiş ve bunu lisansüstü eğitime devam eden bireylerin kampüslerdeki çok kültürlü yapılara daha uzun süreler aşina olduğu ile ilişkilendirmiştir. $\mathrm{Bu}$ çalışmada ise yalnızca genel kültürel zekâ düzeylerinin eğitim durumu ile ilişkisine bakılmış olduğundan elde edilen bulguların uyumlu olduğu görülmektedir. Son olarak, bu çalışmanın bulguları bir başka demografik değişken olarak ele alınan matematik öğretmenlerinin yabancı dil bilme durumlarının kültürel zekâ düzeylerinde anlamlı bir farklılığa neden olduğunu göstermektedir. Alanyazında da genel olarak yabancı dil bilme, yabancı dile hakimiyet, yabancı arkadaşlar edinme ve yabancı ülkelerde bulunma gibi durumların bireylerin kültürel zekalarını olumlu bir şekilde etkilediğini gösteren çalışmalara rastlanılmaktadır (Aksoy, 2013; Aslan ve Kozikoğlu, 2017; Kahraman, 2016). Yabancı dil bilmenin o dilin taşıdığı kültürel yapıyı da öğrenmeyi kolaylaştırdı̆̆ı düşünüldüğünde bireylerin kültürel zekalarının da buna paralel bir şekilde iyileşmesi olağan olarak görülmektedir (İşcan, Karagöz ve Konyar, 2017; Kramsch, 1998).

Özellikle küreselleşen dünyanın, ulaşım ve iletişim olanaklarının gelişmesi ile neredeyse küçük bir köy haline geldiği, ülkeler arası insan akışının hızlandığı günümüzde öğretmenlerin çok kültürlü ortamlarda çalışması kaçınılmaz olmuştur. $\mathrm{Bu}$ nedenle öğretmenlerin çok kültürlü ortamlarda verdiği eğitim ve öğretimin niteliğinin artırılması ve öğretmenlerin farklı kültürlerden öğrencileri eğitim öğretim sürecine dahil edebilmesi için kültürel zekâ kavramı önemli bir anahtar olabilir. Bu bağlamda Early ve Mosakowski’nin (2004) kültürel zekanın geliştirilebileceği, insanların farklı kültürlere daha duyarlı hale getirilerek kültürlerarası iletişim ve etkileşimin verimli hale getirilebileceği vurgusu merkeze alınarak öğretmenlerin kültürel zekâ düzeylerine ilişkin araştırmalar derinleştirilmelidir. Özelde bu çalışma ulaşılabilir 181 öğretmen ile yapılmış olup daha geniş bir örneklemle yapılması önerilmektedir. Buna ek olarak öğretmenlerin kültürel zekâ düzeyleri ile ilişkili olabilecek olan yurt dışında yaşamış olmak, yabancı dil 
bilmek ya da yurt dışında eğitim almış olmak gibi konular araştırılarak konuya yönelik bilgiler detaylandırılabilir (Koçak ve Özdemir, 2015). Ayrıca mevcut durumda görevde olan öğretmenlere verilecek hizmet içi eğitimler ile öğretmenlerin farklı kültürlere yönelik bilgilerinin artırılması ve kültürel zekâ düzeylerine yönelik geliştirme çalışmasının yapılması da önerilir.

\section{Makalenin Bilimdeki Konumu}

Matematik ve Fen Bilimleri Eğitimi Bölümü / Matematik Eğitimi

\section{Makalenin Bilimdeki Özgünlüğü}

Teknolojideki gelişmeler, bilgi ağının genişlemesi ve küreselleşme ülkeler arasındaki mesafeleri ve sınırları kaldırmaktadır. Ülkeler arası bilgi ve insan akış hızının arttığı günümüz 21. yüzyıl dünyasında ülkeler çok kültürlü yapıları barındırır hale gelmiştir. Çok kültürlü toplulukların birbirlerini anlamaları, saygı duymaları ve barış içerisinde yaşamaları için eğitim sistemlerine ve özellikle öğretmenlere önemli görevler düşmektedir. Çok farklı kültürleri bünyesinde barındıran Türkiye'deki matematik öğretmenlerinin kültürel zekâ düzeylerinin belirlenmesi ve konunun farklı değişkenler açısından incelenmesine yönelik bir çalışmaya erişilen literatürde rastlanmamıştır. Bu çalışma ile Türkiye’deki matematik öğretmenlerin kültürel zekâ düzeyleri belirlenerek, öğretmenlerin eğitim düzeyi, cinsiyet, yabancı dil bilme durumu değişkenlerine göre incelenmiştir.

\section{Kaynaklar}

Açıkalın, M. (2010). Sosyal bilgiler eğitiminde yeni yaklaşımlar: Çok kültürlü ve küresel eğitim. Illkögretim Online, 9(3), 1226-1237.

Adıgüzel, O. C. ve Aslım Yetiş, V. (2021). Sınıftaki farklılıklar ile kültürel zekâ: sınıf öğretmeni adaylarının yeterlik algıları ve sınıf öğretmenliği lisans programlarının analizi. Hacettepe Üniversitesi Eğitim Fakültesi Dergisi. Advance online publication. doi: 10.16986/HUJE.2021066858

Aksoy, Z. (2013). Kültürel zeka ve çok kültürlü ortamlardaki rolü (Yayımlanmamış doktora tezi). Ege Üniversitesi Sosyal Bilimler Enstitüsü, İzmir. 
Ang, S. ve Van Dyne, L. (2008). Conceptualization of cultural intelligence: Theory, measurement and applications. Ang, S., \& Van Dyne (Eds), In Handbook of cultural intelligence, 3-15, New York: Routledge.

Ang, S., Van Dyne, L. ve Koh, C. (2006). Personality correlates of the four-factor model of cultural intelligence. Group \& Organization Management, 31(1), 100-123.

Ang, S., Van Dyne, L., Koh, C., Ng, K.Y., Templar, K.J., Tay, C. ve Chandrasekar, N.A. (2007). Cultural intelligence: Its measurement and effects on cultural judgment and decision making, cultural adaptation and task performance. Management and Organization Review, 3(3), 335-71.

Aslan, M. ve Kozikoğlu, İ. (2017). Öğretmenlerin çok kültürlü eğitime yönelik tutumlar: Van ili örneği. Dicle Üniversitesi Ziya Gökalp Eğitim Faültesi Dergisi, 31, 729737.

Banks, J.A. (2013). Çokkültürlü eğitime giriş. (Çev. Aydın, H.). Ankara: Anı Yayınları.

Çetin, Ç. K. (2014). Kültürel zekâ: Uzakyol kaptanları ve uzakyol birinci zabitleri üzerinde bir araştırma. İktisadi ve İdari Bilimler Fakültesi Dergisi, 16(2), 134155.

Çoban, A. E., Karaman Güney, N. ve Doğan, T. (2010). Öğretmen adaylarının kültürel farklılıklara yönelik bakış açılarının çeşitli demografik değişkenlere göre incelenmesi. Abant İzzet Baysal Üniversitesi Dergisi, 10(1), 125-131.

Earley, P. C. (2002). Redefining interactions across cultures and organizations: Moving forward with cultural intelligence. Research in Organizational Behavior, 24, 271299.

Earley, P. C. ve Ang, S. (2003). Cultural intelligence: Individual interactions across cultures. California: Stanford University Press.

Earley, P. C. ve Mosakowski, E. (2004). Cultural ntelligence, Harvard Business Review, 82(10), 139-146.

Eisenberg, J., Lee, H. J., Brück, F., Brenner, B., Claes, M. T., Mironski, J. ve Bell, R. (2013). Can business schools make students culturally competent? Effects of cross-cultural management courses on cultural intelligence. Academy of Management Learning \& Education, 12(4), 603-621. 
Elenkov, D. S. ve Pimenten (2008). Social intelligence, emotional intelligence and cultural intelligence: An integrative perspective. Ang, S., \& Van Dyne (Eds), In Handbook of cultural intelligence, 289-305, New York: Routledge.

Flaherty, J.E. (2008). The effects of cultural intelligence on team member acceptance and integration in multinational teams. Ang, S., \& Van Dyne (Eds), In Handbook of cultural intelligence, 192-205, New York: Routledge.

Fraenkel, J. R. ve Wallen, N. E. (2006). How to design and evaluate research in education. New York: McGraw-Hill.

İlhan, M. ve Çetin, B. (2014). Kültürel zekâ ölçeğinin Türkçe formunun geçerlik ve güvenirlik çalışması. Hacettepe Üniversitesi Eğitim Fakültesi Dergisi, 29(29-2), 94-114.

İnan, K. (2017). Türkçe öğretmeni adaylarında kültürel zekânın çeşitli değişkenlere göre incelenmesi. Hacettepe Üniversitesi Yabancı Dil Olarak Türkçe Araştırmaları Dergisi, 3, 21-33.

İşcan, A., Karagöz, B. ve Konyar, M. (2017). Cultural Transfer and Creating Cultural Awareness in Teaching Turkish as A Foreign language: A Sample From Gaziosmanpaşa University Tömer. Journal of Education and Practice, 8(9), 5364.

İşçi, E., Söylemez, Ö. ve Kaptanoğlu Yıldırım, A. (2013), Örgütlerde kültürel zekâ ve hastane işletmelerinde kültürel zekâ düzeyinin belirlenmesine yönelik bir araştırma, Kafkas Üniversitesi İIBF Dergisi, 4(5), 1-18.

Kahraman, M. (2016). Yabancı dilde kültürel zeka. Eğitim ve Öğretim Araştırmaları Dergisi, 5(2), 12-18.

Karaçam, M. Ş. ve Koca, C. (2012). Beden eğitimi öğretmen adaylarının çok kültürlülük farkındalıkları. Spor Bilimleri Dergisi, 23(3), 89-103.

Khodadady, E. ve Ghahari, S. (2011). Validation of the persian cultural intelligence scale and exploring its relationship with gender, education, travelling abroad and place of living. Global Journal of Human Social Science, 11(7), 64-76.

Kramsch, C. (1998). Language and Culture. Oxford: Oxford University Press.

Koçak, S. ve Özdemir, M. (2015). Öğretmen adaylarının çok kültürlü eğitime yönelik tutumlarında kültürel zekânın rolü. İlkögretim Online, 14(4), 1352-1369. 
Kozikoğlu İ. ve Tosun Y., (2020). Öğretmenlerin kültürel değerlere duyarlı pedagojiye ilişkin görüşleri ile kültürel zekâları arasındaki ilişkinin incelenmesi. Yüksekögretim ve Bilim Dergisi, 10(3), 539-548. https://doi.org/10.5961/jhes.2020.414

Kuzu, Y., Kuzu, O., \& Gelbal, S. (2019). TEOG ve LGS sistemlerinin öğrenci, öğretmen, veli ve öğretmen velilerin görüşleri açısından incelenmesi. Ahi Evran Üniversitesi Sosyal Bilimler Enstitüsü Dergisi, 5(1), 112-130.

Kuzu, O., Kuzu, Y., \& Sivacı, S. Y. (2018). Preservice teachers’ attitudes and metaphor perceptions towards Mathematics. Cukurova University Faculty of Education Journal, 47(2), 897-931.

MacNab, B. R. ve Worthley, R. (2012). Individual characteristics as predictors of cultural intelligence development: The relevance of self-efficacy. International Journal of Intercultural Relations, 36(1), 62-71.

Maden, S. ve Maden, A. (2018). Türkçe öğretmeni adaylarının kültürel zekâ düzeyleri. II. Uluslararası Multidisipliner Kongresi Bildiri Tam Metin Kitabı, 50-67.

Mahasneh, A. M., Gazo, A. M. ve Al-Adamat, O. A. (2019). Cultural Intelligence of the Jordan Teachers and University Students from the Hashemite University: Comparative Study. European Journal of Contemporary Education, 8, 303-314. https://doi.org/10.13187/ejced.2019.2.303

McGregor, J. ve Ungerleider, C. (1993). Multicultural and racism awareness programs for teachers: A meta-analysis of the research. Multicultural education: The state of the art national study report, 59-63, Toronto: Ontario.

Nikoopour, J. ve Esfandiari, N. (2017). The relationship between emotional, social, cultural, spiritual Intelligence and EFL teachers' teaching effectiveness. Journal of Language Teaching and Research, 8(1), 138-148.

Petrović, D. S. (2011). How do teachers perceive their cultural intelligence? ProcediaSocial and Behavioral Sciences, 11, 276-280.

Polat, İ. ve Kılıç, E. (2013). Türkiye'de çok kültürlü eğitim ve çok kültürlü eğitimde öğretmen yeterlilikleri. Yüzüncü Yıl Üniversitesi Eğitim Fakültesi Dergisi, 10(1), 352-372.

Şahin, F. (2011). Liderin kültürel zekâsının astların örgütsel vatandaşlık davranışı ile iş doyumu üzerine etkisi. Savunma Bilimleri Dergisi, 10 (2), 80-104. 
Tan, J. S. (2004). Issues \& observations: Cultural intelligence and the global economy. Leadership in Action: A Publication of the Center for Creative Leadership and Jossey-Bass, 24(5), 19-21.

Tarique, I. ve Takeuchi, R. (2008). Cultural intelligence: The roles of international nonwork experiences. Ang, S., \& Van Dyne (Eds), In Handbook of cultural intelligence, 56-70, New York: Routledge.

Tartwijk, J., Brok, P., Veldman, I. ve Wubbels, T. (2009). Teachers’ practical knowledge about classroom management in multicultural classrooms. Teaching and Teacher Education, 25, 453-460.

Thomas, D. C., Elron, E., Günter, S., Ekelund, B. Z., Ravlin, E. C., Cerdin, J., Poelmans, S., Brislin, R., Pekerti, A., Aycan, Z., Maznevski, M., Au, K. ve Lazarova, M. B. (2008). Cultural intelligence: domain and assessment. International Journal of Cross Cultural Management, 8, 123-143.

Thomas, D. C. ve Inkson, K. (2004). Cultural intelligence: People skills for global business. SanFrancisco: Berrett-Koehler

Yeşil, S. (2010). 21. yüzyılın küresel örgütleri için kültürel zekâ. Çukurova Üniversitesi Sosyal Bilimler Enstitüsü Dergisi, 19(2), 147-168.

\section{Extended Abstract \\ Introduction}

The concept of cultural intelligence first attracted the attention of researchers seeking to identify the most suitable candidate to work abroad or in multicultural settings. Therefore, management and organizational psychology are the fields where the concept of cultural intelligence has been studied the most (Earley \& Ang, 2003; Earley \& Peterson, 2004). The concept of cultural intelligence, which has a wide scope and application area, is the subject of examination of many disciplines which want to understand different cultural environments and the people in these environments. In the field of education, which is one of these branches, the concept of cultural intelligence has been discussed since the 2000s.

In the literature, there are limited number of studies in the field of education, especially for teachers and teacher candidates (Koçak \& Özdemir, 2015). These studies are not directly aimed at cultural intelligence, but their main subject is multiculturalism. 
In some of them, teachers' attitudes towards multicultural education (Çoban, Karaman, \& Doğan, 2010), their level of awareness (Karaçam \& Koca, 2012), and their thoughts on multiculturalism (Tartwijk, Brok, \& Wubbels, 2009) were examined. However, there was no study in the accessed literature, which examines the different variables in terms of determination and cultural issues of very different cultures within the intelligence level of mathematics teachers in Turkey. Therefore, it is important to examine the cultural intelligence level of teachers in Turkey. As a result, with this study, the cultural intelligence levels of the teachers have been determined and the cultural intelligence levels have been examined according to the variables of education level, gender, foreign language knowledge.

\section{The Theoretical Basis of the Study and Related Studies}

While Earley and Ang (2003) defined the concept of cultural intelligence as the ability to work effectively in different cultural environments, the main purpose of cultural intelligence studies is to investigate the reasons for some people's adaptation to different cultural environments (Ang \& Dyne, 2008). Different classifications have been made for the dimensions of cultural intelligence (Thomas et al., 2008). Cultural intelligence, which has a wide scope and application area, has been the subject of research in many different disciplines. Especially in international studies, the comparison of cultural intelligence with other types of intelligence (Elenkov and Pimentel 2008) has been made, and the relationship between five-factor personality traits and four-factor cultural intelligence (Ang, Van Dyne, \& Koh, 2006) have been examined. One of the studies investigating variables that may be related to cultural intelligence level was conducted by Tarique and Takeuch1 (2008) and the relationship between international work experience and cultural intelligence was examined. According to the study, a positive relationship was found between international work experience and cultural intelligence level. In addition, Earley and Ang's (2003) emphasis on the development of cultural intelligence was supported by the studies of Eisenberg, Lee, Brück, Brenner, Claes, Mironski, and Bell (2013). Eisenberg et al. (2013) investigated whether intercultural management lessons influenced students 'cultural intelligence levels and revealed that the lessons had a significant effect especially on students' metacognitive and cognitive dimensions. A limited number of studies on cultural intelligence have been found in Turkey. Yeşil (2010) examined the theoretical framework of the concepts of culture, intelligence, and cultural intelligence. 
Şahin (2011) examined the effects of leaders 'cultural intelligence levels on subordinates' organizational citizenship behavior and job satisfaction in a study. Accordingly, it has been revealed that motivational and behavioral dimensions are effective. In addition, İşçi, Söylemez, and Kaptanoğlu-Yıldırım (2013) determined the cultural intelligence levels of healthcare workers and it was determined that the duration of working in the institution and in the profession has a weak negative relationship with the behavioral dimension and general score of cultural intelligence. In another study, the cultural intelligence levels of the distant road captains and the distant road first minute's clerks who interacted with different cultures were examined, and the cultural intelligence of the participants in the motivational dimension was found to be higher with a significant difference, followed by the metacognitive dimension (Çetin, 2014). The relationship between attitudes toward multicultural education with cultural intelligence of teacher candidates were investigated in the study of Koçak and Özdemir (2015). The study revealed that there is a positive relationship between cultural intelligence and attitude towards multicultural education, and demographic variables and three dimensions of cultural intelligence (metacognition, motivation, and behavior) were found to be significant predictors of attitude towards multicultural education.

\section{Method}

In this study, it was aimed to investigate the cultural intelligence levels of teachers and to examine their cultural intelligence levels according to their education levels, genders, and knowledge of foreign languages. Survey model was used in accordance with the purpose of the study. In particular, cross-sectional survey model was used in this study, and data were collected from teachers by using the Cultural Intelligence Scale. The sample of this study consists of a total of 181 teachers from 26 provinces of Turkey. 133 of the participants were female (73.5\%) and 48 were male (26.5\%). Moreover, $61.9 \%$ of the participants have undergraduate degree, $26.5 \%$ of them have graduate degree and $11.6 \%$ of them have doctorate degree.

The Cultural Intelligence Scale (CQS), developed by Ang et al. (2007) and adapted into Turkish by İlhan and Çetin (2014), was used as the research instrument of the study. The scale used has a 7-point Likert type rating that range between "I do not agree at all" and "I totally agree". The scale consists of 20 items and consists of 4 subdimensions: metacognition, cognition, motivation, and behavior. The total variance 
explained in the adaptation study (İlhan \& Çetin, 2014) of the scale was calculated as $52.66 \%$ and the reliability coefficient for the whole scale was calculated as .85. In this research, CQS was sent to the e-mail addresses of the teachers and was requested to be filled online. During the data collection phase, teachers were informed that the survey took approximately 15 minutes to complete.

\section{Results}

Data were analyzed using arithmetic mean, standard deviation, independent samples t-test, one-way analysis of variance (ANOVA). First of all, mathematics teachers' cultural intelligence levels were determined $(\mathrm{M}=5.29$, $\mathrm{SD}=.99)$, as well as their levels in metacognition dimension $(M=5.88, S D=1.03)$, cognition dimension $(M=4.65$, SD = 1.20), behavior dimension $(M=5.25, S D=1.28)$ and motivation dimension $(M=563$, $\mathrm{SD}=1.26)$. According to the findings related teachers' scores in CQS, teachers' levels in cultural intelligence and its dimensions were close to 5 out of 7 and thus their cultural intelligence levels were found high.

According to Pearson Correlation test, there was a significant relationship among the dimensions of cultural intelligence (metacognition, cognition, motivation and behavior) $(\mathrm{p}<.05)$. The relationship levels of the dimensions were measured as medium. In addition, the direction of these relationships was found positive for all dimensions. In other words, for instance, an individual with high cultural intelligence in the metacognitive dimension is expected to have higher scores in other dimensions. In order to investigate teachers' cultural intelligence levels in terms of their gender, a t-test was conducted. The result of this analysis showed that there was no significant difference in cultural intelligence level between men and women mathematics teachers. Moreover, in order to investigate teachers' cultural intelligence levels regarding their proficiency about foreign languages, a t-test was conducted, and the result revealed a significant difference between the cultural intelligence level of those who speak a foreign language and those who do not $(\mathrm{p}<.05)$. In other words, mean scores in CQS of teachers who speak a foreign language were found significantly higher than those who do not speak a foreign language. In addition, in order to investigate their cultural intelligence levels with respect to their education status, ANOVA test was conducted, and the cultural intelligence levels of the teachers did not show a significant difference according to their educational status ( $\mathrm{F}=$ 1.471, $\mathrm{p}>.05)$. 


\section{Discussion and Conclusion}

In this study, it was found that the teachers who participated in the study had high levels of cultural intelligence. In particular, the cultural intelligence dimensions were examined, and it was found that the mean scores of the metacognition dimensions were higher than the other dimensions. In addition, it was determined that there were significant relationships between the dimensions of cultural intelligence. For example, it was found that an individual with a high metacognitive intelligence dimension was expected to have higher scores of other dimensions. Moreover, in the context of this study, cultural intelligence levels of teachers were investigated in terms of their genders, education levels and foreign languages knowledge. According to results, while gender and educational status did not make a difference in cultural intelligence levels, it had been determined that there was a significant difference between the cultural intelligence levels of those who speak a foreign language and the ones not speaking a foreign language. It has become inevitable for teachers to work in multicultural environments, especially in today's world. Since, teachers works in such classes which consists of students from different cultures, the concept of cultural intelligence can be an important key to increase the quality of education and training given by teachers in multicultural environments. In this context, Early and Mosakowski (2004) emphasized that cultural intelligence can be developed, that intercultural communication and interaction can be made efficient by making people more sensitive to different cultures, and research on the cultural intelligence levels of teachers should be deepened. 